\title{
The use of chromic catgut in the primary closure of scalp wounds in children
}

\author{
N. J. START, A. M. ARMSTRONG \& W. J. ROBSON
}

Accident and Emergency Department, Royal Liverpool Children's Hospital. (Alder Hey), Liverpool, England

\section{SUMMARY}

A prospective clinical trial examining the benefits of using an absorbable suture for the closure of scalp wounds, is described.

One hundred wounds were included, of which 50 were closed with chromic catgut, and 50 were closed with silk. On examination 5 days later, there were no complications in either group.

The advantages of using an absorbable suture material in children's scalp wounds are discussed.

\section{INTRODUCTION}

Children with scalp wounds constitute a large part of the workload of an accident and emergency department. Many of these wounds require closure, and the most commonly used method is suturing. This is invariably traumatic for the child, and if nonabsorbable sutures are used there is the added trauma of removal. Many children have to return to the accident and emergency department for suture removal, either because their own general practitioners do not provide such a service, or because more than one person is required to remove the sutures safely.

Return to the hospital can add considerably to the inconvenience for parent and child, both in time spent in travelling and waiting, and in cost. It also adds to the workload of the department.

The use of absorbable sutures therefore has definite advantages. They are not invariably used however, and until recently, it was the policy of this Department to use silk to close scalp wounds.

Correspondence: N. F. Start, Accident and Emergency Department, Royal Liverpool Children's Hospital (Alder Hey), Liverpool, England. 
A study was planned to investigate whether the use of an absorbable suture would improve the management of patients with scalp wounds. Chromic catgut was chosen because of its greater tensile strength over plain catgut.

The trial was designed to demonstrate any complications of wound healing, to assess the time taken for the absorbable sutures to fall out, and to examine parental satisfaction.

\section{METHOD}

Any child attending the Accident and Emergency Department of the Royal Liverpool Children's Hospital (Alder Hey), with a scalp wound requiring closure, was entered into the trial, until 100 patients were recruited. Alternate patients were allocated to chromic catgut (4/0) and silk (4/0).

All wounds were reviewed 5 days later by a doctor. The silk sutures were removed, whilst the catgut sutures were inspected only.

The appearance of the wound was recorded, and any complications noted. The parents were asked about the cost of travelling back to the Accident and Emergency Department, the time spent and whether they preferred the wound to be inspected again.

The parents of children with chromic catgut sutures were given a postal questionnaire to be completed once the sutures had fallen out, recording the time taken, and any complications.

\section{RESULTS}

One hundred patients were entered into the trial. Of those sutured with silk, 48 returned for removal of sutures at 5 days. Of those sutured with catgut, 42 were reviewed at 5 days and returned completed questionnaires, or were contacted by telephone.

\section{Parental preference}

Seventy-nine percent of parents would have preferred not to return to the Accident and Emergency Department. Twelve percent preferred to attend for review. Nine percent had no preference.

\section{Complications}

No complications of healing were noted in either group.

Time for sutures to fall out

In 36 patients the sutures had fallen out by 2 weeks, and in a further four patients the 
sutures had fallen out by 4 weeks. In the remaining 2 patients the sutures were removed at 4 weeks because of parental concern over the persistence of the sutures. In no patients did the prolonged retention of sutures cause any problem.

Parental time and cost

The time and average cost of a return visit to the Accident and Emergency Department was surprisingly high, being $2 \frac{1}{2} h$ and $£ 4.75$ respectively.

\section{DISCUSSION}

Suturing is accepted as being an effective method of managing scalp wounds which require closure. Other methods are the use of steristrips and the use of Histoacryl tissue adhesive (Morton et al., 1988).

The use of steristrips is limited because of the necessity of having bare skin around $\mathrm{O}$ the wound. Other limitations are the need for good haemostasis prior to closure, and good patient compliance. Scalp wounds heal very well and rarely become infected (Howell et al., 1988). One previous study showed that a synthetic absorbable suture was acceptable as a means of wound closure in accident and emergency (Adams, 1977).

By using an absorbable suture the return visit is unnecessary, saving the child the trauma of suture removal, and saving substantial time and money for the parent. The workload of the Department is reduced also, thereby decreasing waiting time and saving the cost of instrument sterilization.

There were no complications of wound healing when chromic catgut sutures were used. In six patients however, sutures remained in situ for up to 4 weeks, and in two patients they were removed. This was acceptable to the patients involved and their parents, causing no pain or other problems.

Parents should be warned that sutures usually fall out at 2 weeks but may take longer. Should this be unacceptable, then it is always possible to remove them.

There is no significant difference in cost. A $4 / 0$ chromic suture of $75 \mathrm{~cm}$ length costs $£ 0.85$ compared with $£ 0.70$ for a corresponding silk suture of $45 \mathrm{~cm}$ length.

\section{CONCLUSION}

Chromic catgut is an acceptable suture material for closure of scalp wounds and has definite advantages over silk.

\section{ACKNOWLEDGEMENT}

The authors thank the staff of the Alder Hey Accident and Emergency Department for their help in conducting this study, and Miss C. Widders for typing the manuscript. 


\section{REFERENCES}

Adams I. W. \& Bell M.S. (1977) A comparative trial of polyglycolic acid and silk as suture material for accidental wounds. Lancet, 2, 1216-7.

Howell J. M. \& Morgan J. A. (1988) Scalp laceration repair without prior hair removal. American fournal of Emergency Medicine 6, 7-10.

Morton R. J., Gibson M. F. \& Sloan J. P. (1988). The Use of Histoacryl tissue adhesive for the primary closure of scalp wounds Archives of Emergency Medicine 5, 110-2. 